\title{
Artificial Neural Network - based Efficiency Maximization of a Variable Frequency Induction Motor Drive
}

\author{
By \\ F.M. El-Khouly and F.E. Abdel Kader \\ Department of Electrical Eng., Faculty of Eng,, Menoufia University, Shebin El-Kom, Egypt.
}

\begin{abstract}
There exists a combination of stator voltage and frequency which results in maximum efficiency for a given induction motor under a specified speed and load condition. This optimal operating point is calculated over the complete speed and load torque range using an Artificial Neural Network (ANN). It is shown that maximum efficiency can be achieved compared to the conventional volt/hertz control method. Theoretical results are presented as well as an experimental confirmation of them.
\end{abstract}

\section{Introduction}

Due to the wide application in process industries, the problem related to the efficiency maximization of induction motor has received much attention [1-2].

Conventionally, the air-gap flux of a motor is maintained at a nominal value throughout the whole speed range, thus achieving a high utilization of the motor iron and permitting the development of the rated torque at all supply frequencies. However, at a light load, the motor flux is greater than necessary for the development of the required torque, and loss is high, resulting in poor motor efficiency. Its efficiency can be improved by reduction of the air-gap flux to a value suitable for the reduced torque.

The effect of flux level on the efficiency of an induction motor can be understood from [3-6]. The combination of stator voltage and frequency, which minimizes the induction motor losses, was shown to be complex function of the operating

Manuscript received from Dr. F.M. EL-KHOULY on : 11/3/2000

Accepted on : 26/3/2000

Engineering Research Bulletin, Vol 23,No 2, 2000 Minufiya University, Faculty of Engineering, Shebien EI-Kom, Egypt, ISSN 1110-1180 
speed and torque [4]. Optimal efficiency thus cannot be achieved by implementing a fixed relation between stator frequency and voltage. Optimal efficiency was calculated in [7] by direct measurement of the motor power input and the implementation of an adaptive controller to the indirect field oriented induction motor drive. An adapted field oriented mechanism with detuning correction and efficiency optimization of an indirect field oriented induction motor speed drive is presented in [8]. Two fuzzy controllers were used in that adapted field oriented mechanism.

In this paper $\mathrm{ANN}$ is used to calculate the motor applied voltage and frequency which maximize the efficiency for the whole operating range of motor torque and speed.

\section{Model of Induction Machine}

The per phase equivalent circuit of an induction motor is shown in Fig. (1). From the equivalent circuit, the rotor current can be given by :

$$
I_{r}=\frac{E_{1}}{\left[\left(\frac{R_{2}}{s}\right)^{2}+X_{2}{ }^{2}\right]^{\frac{1}{2}}}
$$

with,

$$
X_{2}=X_{20}\left(\frac{f_{s}}{50}\right)
$$

Where $E_{1}$ is the stator EMF per phase, $s$ is the slip, $f_{s}$ is the motor input frequency, $\mathrm{X}_{20}$ is the rotor leakage reactance at standstill and nominal frequency equals $50 \mathrm{~Hz}, \mathrm{R}_{2}$ and $\mathrm{X}_{2}$ are the rotor resistance and leakage reactance, respectively, at any supply frequency. All rotor values are referred to stator side.

If $W_{\mathrm{r}}$ is the mechanical angular velocity of the rotor, the torque is given by :

$$
T=\frac{m_{1} I_{r}^{2} R_{2}}{\omega_{r}} \frac{(1-s)}{s}
$$

Where $m_{1}$ is the number of stator phases. On combining this expression with equation (1), the torque equation is :

$$
T=\frac{p m_{1} E_{1}^{2}}{2 \pi f_{s}} \frac{R_{2} / S}{\left[\left(R_{2} / s\right)^{2}+X_{2}{ }^{2}\right]}
$$

Where $p$ is the number of pole pairs.

For a given value of $T, f_{s}$ and $E_{1}$, the slip and then the total impedance of the circuit of Fig. (1) can be calculated. So, the stator current $\left(\mathrm{I}_{1}\right)$, the input voltage 
$\left(\mathrm{V}_{1}\right)$, the input power factor, the copper loss $\left(\mathrm{P}_{\mathrm{cu}}\right)$, the iron loss $\left(\mathrm{p}_{\mathrm{i}}\right)$, and efficiency can be calculated.

The induction motor under study has the following data: $220 \mathrm{~V}, 3.5 \mathrm{~A}, 1445 \mathrm{rpm}$ and has the following parameters: $R_{1}=3.4 \Omega, X_{1}=7.37 \Omega, R_{2}=4.75 \Omega, X_{20}=$ $17.45 \Omega, \mathrm{Rm}=1700 \Omega$, and $\mathrm{Xm}=195 \Omega$. A computer program is written to demonstrate the effect of the motor input voltage on the motor efficiency. Figs. $(2-a, b)$ show the variation of the motor efficiency with motor input voltage at different loads for supply frequency equals $50 \mathrm{~Hz}$ and $20 \mathrm{~Hz}$, respectively. From the figures it is shown that for any load and supply frequency there exist a specified supply voltage at which the efficiency has its maximum value.

\subsection{Motor parameters variation}

Usually, the variation of motor parameters with voltage and frequency is neglected and the motor model is then considered to be linear. Actually, the motor parameters are varying with the input voltage and frequency. The effect of taking these parameters variations in the calculation of the optimal operating conditions will be considered in this section.

The induction motor iron losses are usually modeled by a resistor connected in parallel with magnetizing reactance. These losses include both hysteresis loss and eddy current loss. The hysteresis losses are proportional to the frequency and eddy current losses to the square of the frequency. Based on these assumptions, the equivalent core loss resistance taking the effect of frequency variation is [ 9]:

$$
R_{m}^{\prime}=R_{m}\left(\frac{50}{f_{s}}\right)^{1 . l}
$$

where $R_{m}$ is the iron loss resistance at nominal frequency equals $50 \mathrm{~Hz}$ and rated voltage equals 220 volt.

Also, the iron losses are affected by the value of applied voltage. These losses are proportional to the square of flux density. So, the equivalent iron loss resistance is modified to take the effect of magnetic saturation by [ 9 ]:

$$
R_{m}^{\prime \prime}=R_{m}^{\prime}\left(\frac{I_{m}}{I_{m}^{\prime}}\right)^{2}
$$

where $I_{m}$ and $I_{m}$ are magnetizing current at any motor input voltage and at the nominal input voltage, respectively.

From equations 5 and 6 the combination effect of the induction motor input voltage and frequency on the iron losses resistance can be expressed as:

$$
R_{m}^{n}=R_{m}\left(\frac{50}{f_{s}}\right)^{1.1}\left(\frac{I_{m}}{I_{m}^{\prime}}\right)^{2}
$$


Also, the saturated value of magnetizing reactance is obtained experimentally. Its value is determined theoretically during the calculation procedure using look-up table and linear interpolation method.

Figs. (3-a,b) show that variation of both iron losses resistance and the magnetizing reactance, respectively, with the input voltage at rated frequency. Fig. (3-c) indicates the variation of the iron loss resistance with motor input frequency at rated voltage. The motor model with parameter variations will be denoted as nonlinear model.

Computer programs are written to study the motor performance with linear and nonlinear models. Figs. $(4-a, b)$ indicate the variation of the input voltage that maximizes the motor efficiency with the input frequency at two load torque equal $2 \mathrm{Nm}$ and $8 \mathrm{Nm}$, respectively. The solid and dashed lines represent the nonlinear and linear model, respectively. Figs. $(5-a, b)$ indicate the variation of the maximum efficiency with frequency for the same loads of the previous figure. From the figures it is seen that there are a significant differences between the two models. Fig. (6-a) indicates the variations of the motor optimal slip with input frequency at different loads for the linear model, while Fig. (6-b) shows the same variations for the nonlinear model. It can be seen that at a definited frequency the optimal speed is varied with load for the nonlinear model, while it is almost constant for the linear model. From the above results it can be concluded that the effect of motor parameters variation due to the variations of input voltage and frequency must be taken into consideration.

Fig. (7) represents the variation of the maximum efficiency with input frequency at different loads. The efficiency at different loads for constant volt $/ \mathrm{Hz}$ is also represented in this figure to show the difference with the maximum possible efficiency.

Fig. (8) shows the optimal input voltage and constant volt/Hz with input frequency at different loads. From the figure it can be seen that the optimal applied voltage might be greater or less than the constant volt $/ \mathrm{Hz}$ according to the applied frequency and load torque. The optimal voltage has a limit value to prevent the motor total losses not to exceed the nominal losses at rated voltage and frequency.

\section{Definition of the problem and solution by ANN}

The following problem is considered: for a given operating point defined by the load torque and the command motor speed, find the input motor voltage and frequency which minimize the input power to the motor. This set of values of the input variables characterizes the optimal operating point and results in minimum losses operation under the specified external constraints. An on-line analytical solution of this problem cannot be found if a complete model of the machine 
including the motor parameter variation with input voltage and frequency (nonlinear model) are considered.

\subsection{Artificial neural network (ANN)}

Recently, several studies have independently found that a three-layer ANN using the back propagation algorithm approximate a wide range of nonlinear functions to any desired degree of accuracy [10-11]. In this section, three layers feedforward ANN is used to approximate the relation between the motor load torque and speed as inputs with motor optimal input voltage and frequency as outputs. Sets of training patterns are obtained using the computer program for the nonlinear motor model and the optimal input voltage and frequency is obtained for a specified motor torque and speed. These patterns are used to train the ANN which consists of two neuron in the input layer, one hidden layer with 25 neurons, and an output layer with two neurons. The neurons in the hidden layer have tansigmoid activation function while neurons in the output layer have logsigmoid activation function.

An adaptive learning rate is used to accelerate the training process. This adaptive learning rate requires some changes to the traditionally constant learning rate training procedure. First the initial ANN outputs and the errors between this outputs and the targets are calculated. At each epoch new weights and biases are calculated using the current learning rate. New outputs and errors are then calculated. If the new errors exceed the old errors by more than a predefined ratio (typically 1.04), the new weights, biases, outputs, and errors are discarded. In addition, the learning rate is decreased (typically by multiplying by 0.7 ). Otherwise, the new weights, etc., are kept. If the new errors are less than the old error, the learning rate is increased (typically by multiplying by 1.05 ). This procedure increases the learning rate, but only to the extent that the network can learn without large increase of errors. Thus a near optimal learning rate is obtained. When a larger learning rate could result in stable learning, the learning rate is increased. When the learning rate is too high to guarantee a decrease in the ANN output errors, it gets decreased until stable learning resumes.

During the training process, Figs. (9-a,b) show the variations of the learning rate and the sum squared errors with epoch, respectively.

\subsection{Simulation results}

After training the ANN, it is tested to deduce the optimal operating point and compared with the actual results. Fig.(10) represents the optimal input voltage versus motor speed at different loads. The solid lines represent the actual values and the dotted lines represent the ANN outputs. Also, the optimal value of input frequency for any speed and two different loads $(3 \mathrm{Nm}$ and $6 \mathrm{Nm}$ ) are shown in Figs. (11-a,b). These figures validate the effectiveness of the proposed ANN to 
optimize the induction motor operation.

The trained ANN is then cascaded with the induction motor and inverter set as shown in Fig. (12). A computer program is written to study the steady state motor performance with the proposed ANN. Fig. (13) represents the variation of the maximum efficiency with motor speed at different loads. Figs. (14-a,b,c,and d) show the optimal values of motor input current, motor power factor, motor iron losses, and motor total losses, respectively, with motor speed at different loads.

\subsection{Experimental results}

Experimental results are deduced to check the validity of the proposed ANN based optimization method for the nonlinear induction motor model. The tests are deduced at constant speed and load torque to maintain constant output power during the test. The input motor frequency of the induction motor is adjusted to keep the speed constant while the input voltage is varied. Since the test motor is connected to a separately excited DC motor, the load torque is automatically held constant if the speed remains unchanged.

In the test, the voltage is varied over a wide range encompassing the theoretical optimal value in order to find the value resulting in the minimum input power for two different operating points. These results, given in Table I, show that the actual optimal voltage and frequency are very close to the calculated values.

\section{4-Conclusions}

This paper presents an on-line optimal efficiency operation method based on ANN for variable frequency induction motor. This method is capable to minimize the motor losses over different loads and speed range up to twice the rated speed. It can be seen that the effect of magnetic saturation and frequency changes on motor parameters must be considered in case of optimal efficiency. For light loads the optimal input voltage is less than the traditional constant volt $/ \mathrm{Hz}$ method while it is greater for large loads. Also, it can be noted that for high loads, there is a maximum limit of speed to operate under optimal efficiency condition. This is to prevent the motor losses not to exceed its nominal value and so prevent motor overheating.

\section{5-References}

[1] N. Mohan,"Improvement in Energy Efficiency of Induction Motors by Means of Voltage Control," IEEE Trans. Power Appr. Syst., vol. PAS-99, July/Aug., 1980.

[2] M.H. Park and S.K.Sul,"The Microprocessor Based Optimal Efficiency Drive of Induction Motor," in IEEE IECI Peoc., 1981.

[3] H.G. Kim, S.K. Sul and M.H. Park,"Optimal Efficiency Drive of a Current 
Source Inverter Fed Induction Motor by Flux Control," IEEE Trans. on Ind. Appl., vol. IA-20, No. 6, Nov./Dec., 1984.

[4] D.S. Kirschen, D.W. Novotony and W. Sunwanwisoot,"Minimising Induction Motor loss by Excitation Control in Variable Frequency Drives," IEEE Trans. Ind. Appl., IA-20, (1), 1984, pp.1244-1250.

[5] D.S. Kirschen, D.W. Novotony and T.A. Lipo,"Optimal Efficiency Control of an Induction Motor Drive," IEEE Trans. Energy Convers., EC-2, (1), 1990, pp.70-75.

[6] A. Kusko and D. Galler,"Control Means for Minimization of Losses in AC and DC motor Drives," IEEE Trans. in Inds. Appl., vol. IA-19, No. 4, July, Aug., 1983, pp. 561-570.

[7] D.S. Kirschen, D.W. Novotony and T.A. Lipo,"On-Line Efficiency Optimization of a Variable Frequency Induction Motor Drive," IEEE Trans. on Ind. Appl., vol. IA-21, No. 4, May/June, 1985, pp.610-616.

[8] J.B. Wang and C.M. Liaw,"Indirect Field Oriented Induction Motor Drive with Fuzzy Detuning Correction and Efficiency Optimisation Controls," IEE Proc. Electr. Power Appl., Vol. 144, No. 1, January, 1997, pp.37-45.

[9] S.A. Kaliah, M.Z. El-Sherief and F.E. Abdel Kader,"New Philosophy for Improved Performance of Induction Motor Operating From Frequency Converter", Proc. 2nd Int. Conf. on Eng. Research, Vol. 1,Dec. 19995, pp. 42-54, port-Said, Egypt.

[10] K. Hornik, M. Stinchcombe and H. White,"Multilayer Feedforward Neural Networks are Universal Approximators", IEEE Trans. Neural Network, Vol. 2, 1989, pp.359-366.

[11] K.J. Hunt and D. Sbarbaro, "Neural Networks for Nonlinear Internal Model", IEE Proceedings, D, Vol. 138, No. 5, Sept., 1991, pp. 431-438. 


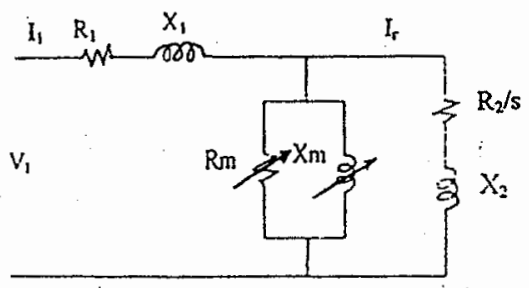

Fig.(1) The proposed per phase equivalent circuit of induction motor.

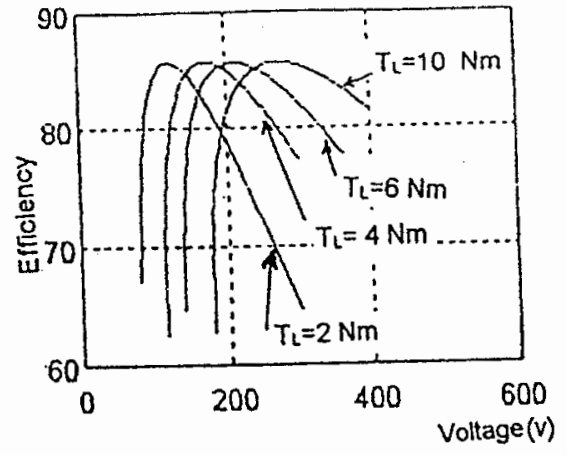

Fig. (2-a)At $f_{s}=50 \mathrm{hz}$.

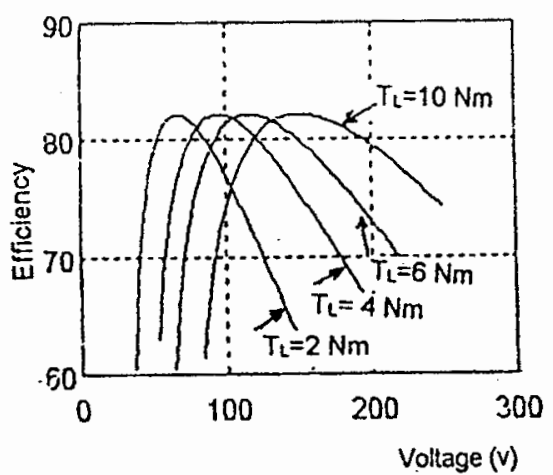

Fig.(2-b) At $f_{s}=20 \mathrm{hz}$.

Fig.(2), Variation of the motor efficiency with motor input voltage at different lcads.

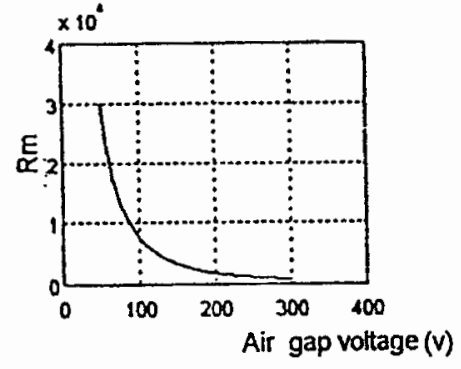

Fig.(3-a) Variation of iron losses resistance with input voltage at rated frequency.

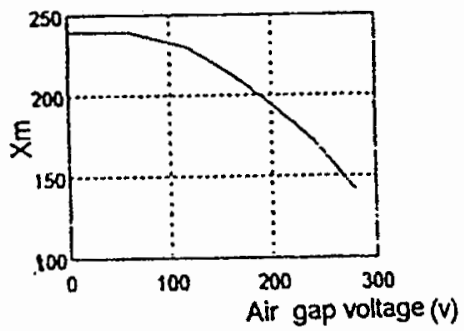

Fig.(3-b) Variation of magnetising reactance with input voltage at rated frequency.

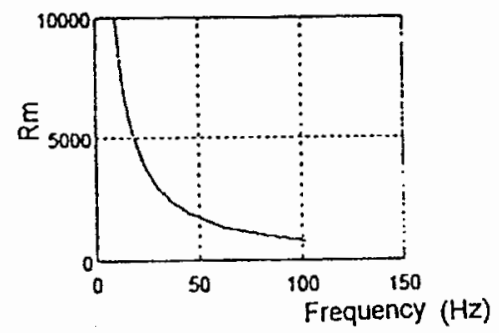

Fig.(3-c) Variation of iron losses resistance with input frequency at rated voltage.

Fig.(3) molor parameters variation with the input motor voltage and frequuency 


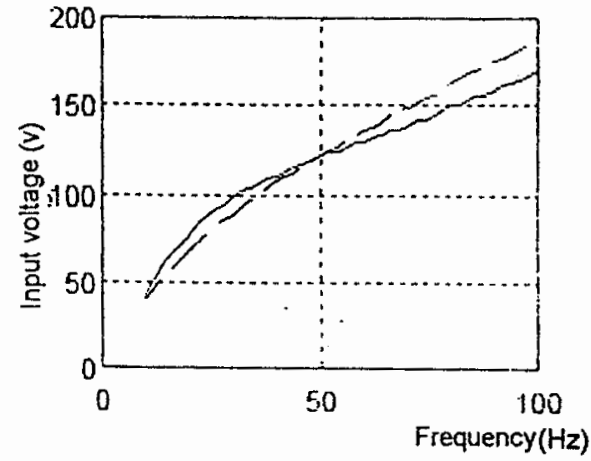

Fig.(4-a) Load torque $\left(T_{L}=2 \mathrm{Nm}\right)$

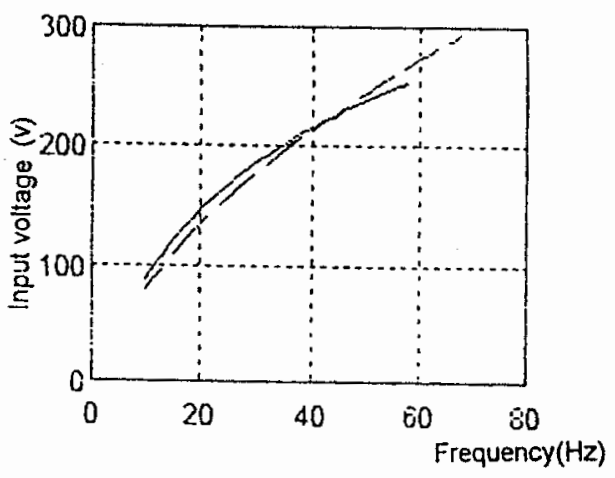

Fig.(4-a) Load torque $\left(T_{l}=8 \mathrm{Nm}\right)$

Fig.(4) Variation of the input optimal voltage with the input frequency. (__ nonlinear model _-linear model)

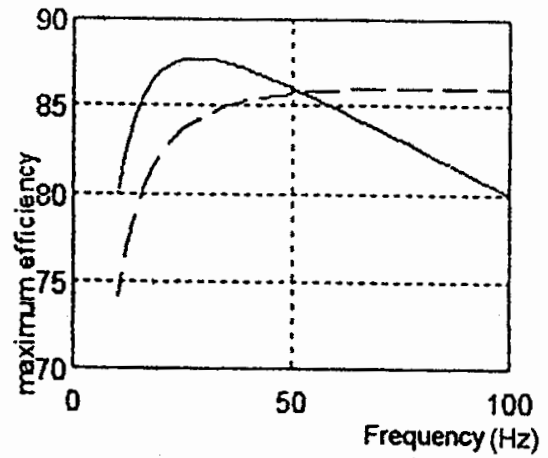

Fig.(5-a) Load torque $(T L=2 \mathrm{Nm})$

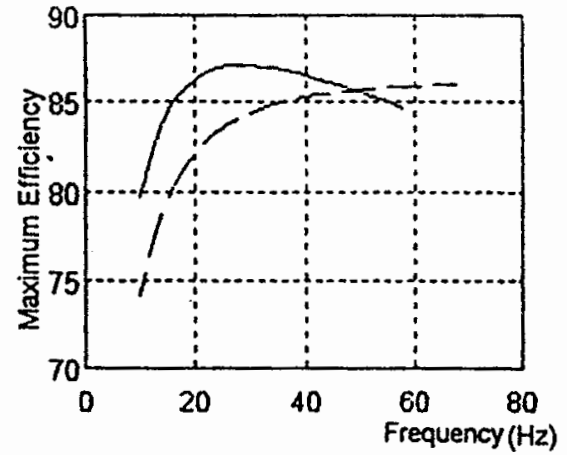

Fig.(5-b) Load torque $(\mathrm{TL}=8 \mathrm{Nm})$

Fig.(5) Variation of optimal efficiency with the input frequency. $\_$_ nonlinear model — linear model)

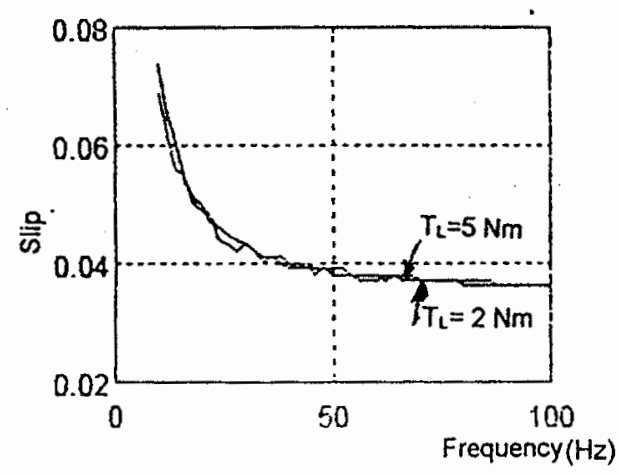

Fig.(6-a) Linear model

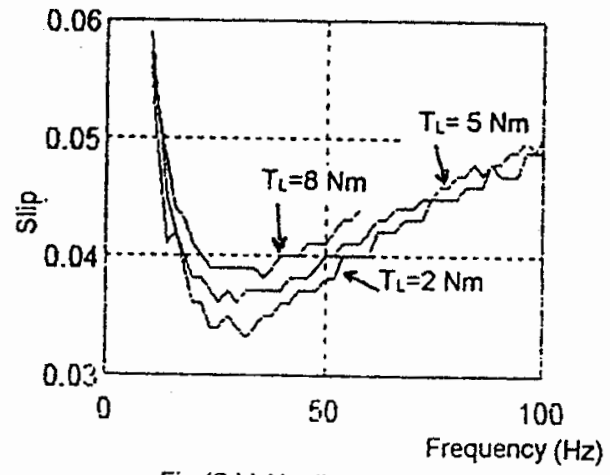

Fig.(6-b) Nonlinear model.

Fig.(6) Variations of the motor optimal slip with input frequency at different loads. 


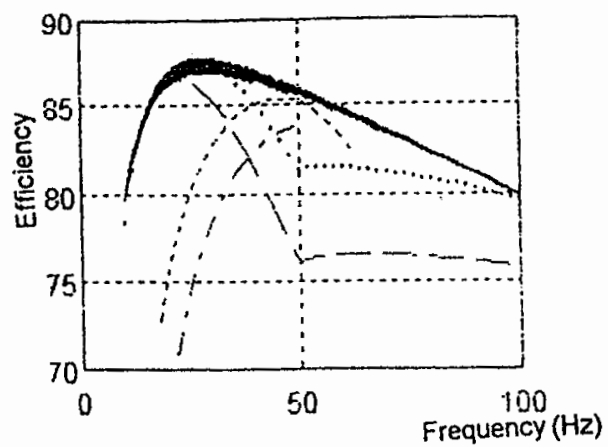

Fig.(7) Variation of efficiency with input frequency at different loads optimal efficiency for loads from $1 \mathrm{Nm}$ to $10 \mathrm{Nm}$ )

(For constant volt/ $\mathrm{Hz}:-\mathrm{T}_{\mathrm{L}}=2 \mathrm{Nm}, . . \mathrm{T}_{\mathrm{L}}=3 \mathrm{Nm}$, $--T_{L}=8 \mathrm{Nm},-,-T_{L}=10 \mathrm{Nm}$ ).

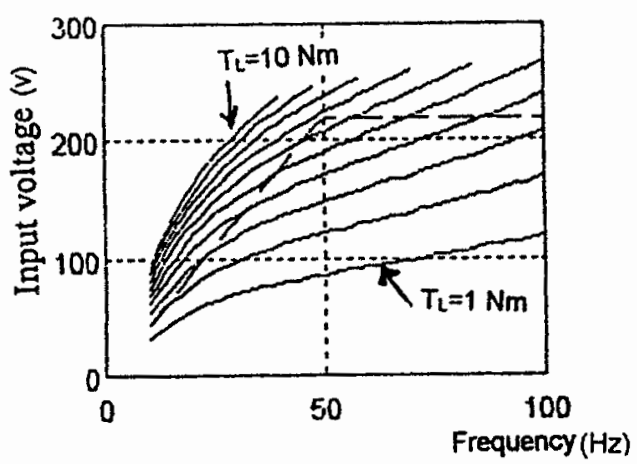

Fig.(8) Variations of the optimal input voltage and constant volt $\mathrm{Hz}$ with input frequency at different loads.

__ Optimal voltage for loads from $1 \mathrm{Nm}$ to $10 \mathrm{Nm}$. - - constant volt/ $\mathrm{Hz}$ for all loads).
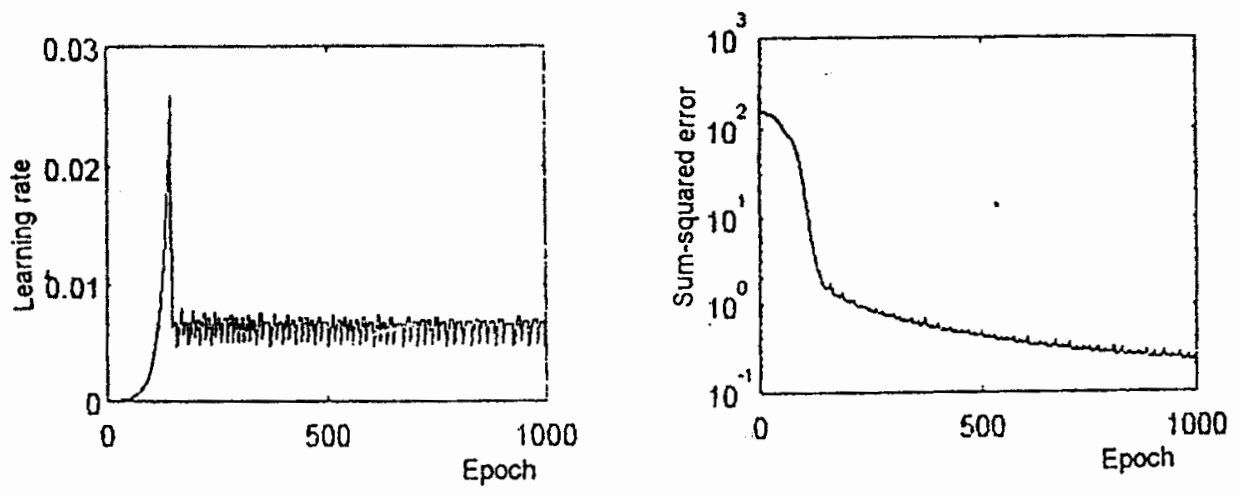

Fig.(9-a) Variation of the learning rate with epoch.

Fig.(9-b) Variation of the sum squared errors with epoch.

Fig.(9) Training The ANN. 


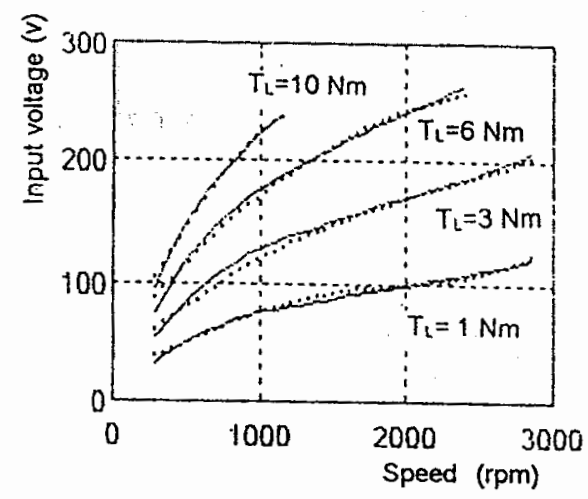

Fig.(10) Variation of optimal input voltage with motor speed at different loads. $\_$actual value, - ANN output).

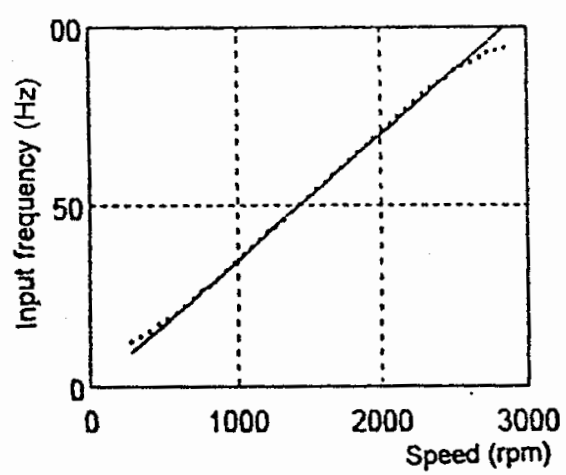

Fig.(11-a) TL $=3 \mathrm{Nm}$.

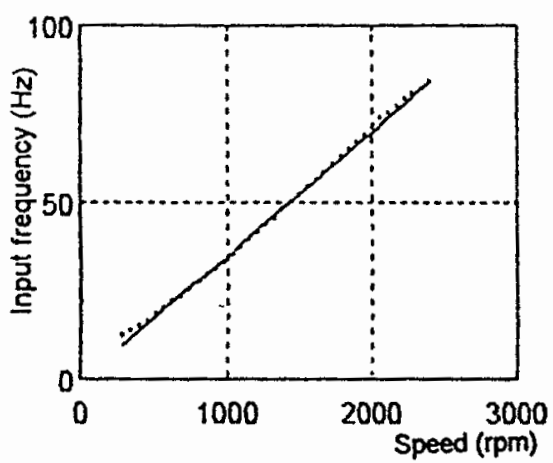

Fig. $(11-b) T L=6 \mathrm{Nm}$.

Fig.(11) The optimal value of optimal input frequency for any. speed. Lactual value, - ANN output).

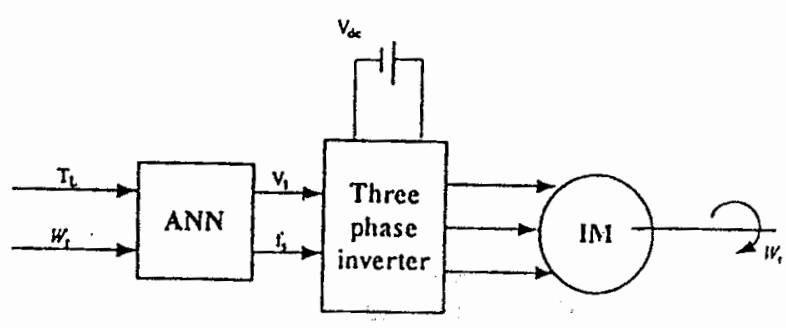

Fig.(12) The system with the proposed ANN.

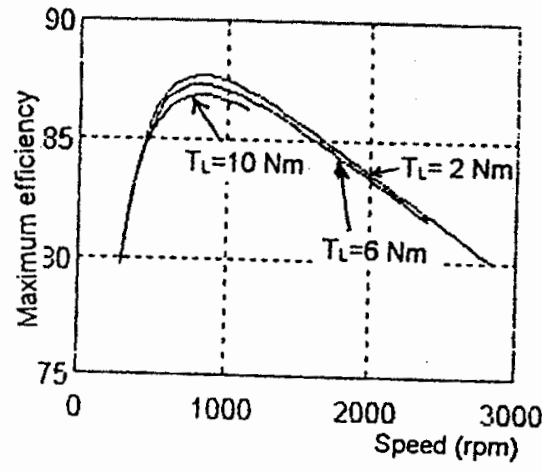

Fig.(13) The proposed ANN-based optimal efficiency variation with motor speed at different loads. 


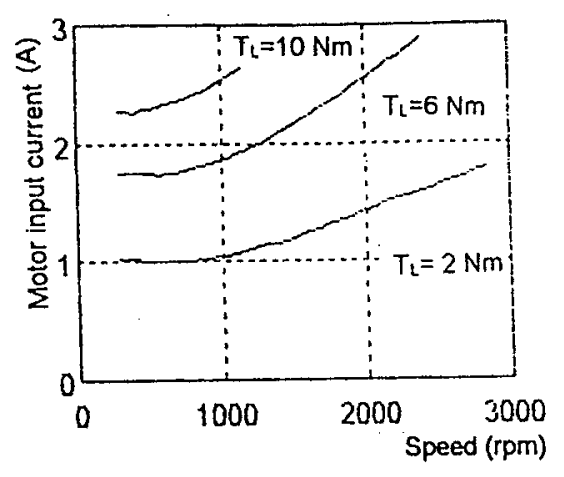

Fig.(14-a)

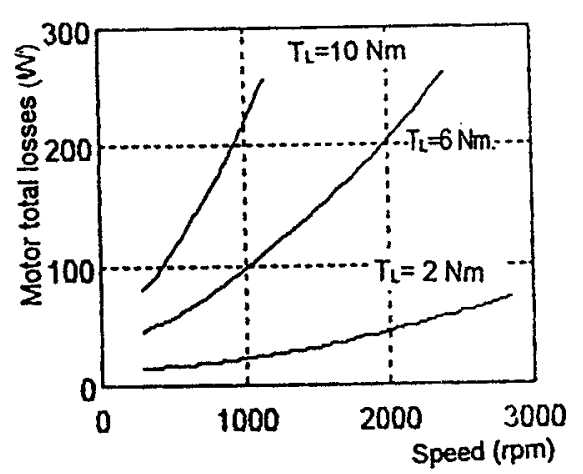

Fig.(14-c)

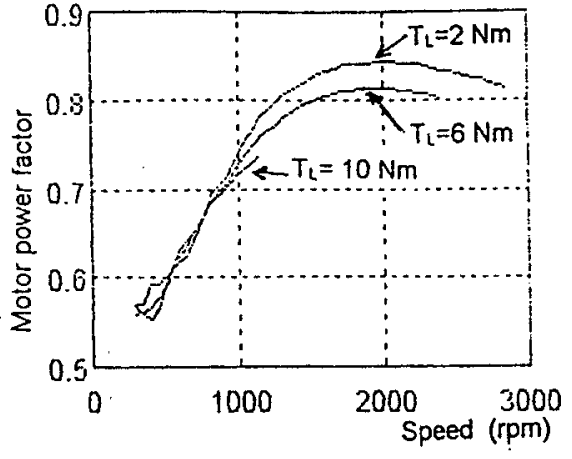

Fig.(14b)

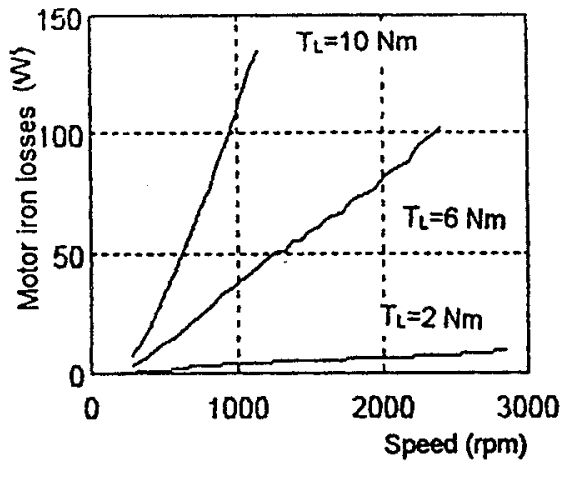

Fig.(14-d)

Fig.(14) Motor performance with the proposed ANN.

TABLE I Measured and calculated optimal input voltage and frequency for two operating points

\begin{tabular}{|c|c|c|c|c|}
\hline \multirow{7}{*}{$\begin{array}{l}\text { POINT(I) } \\
T_{L}=2(N M) \\
\text { Speed }=865 \\
(\text { (pm) }\end{array}$} & \multirow{7}{*}{$\begin{array}{l}\text { PROPOSED } \\
\text { THEORITICAL } \\
\text { RESULTS } \\
\text { oplimal vollage } \\
=122(\mathrm{v}) \\
\text { Oplimal freque. } \\
=50(\mathrm{~Hz})\end{array}$} & \multicolumn{3}{|c|}{ EXPERIMENTAL RESULTS } \\
\hline & & Inpul vollage & $\begin{array}{l}\text { input } \\
\text { frequency }\end{array}$ & $\begin{array}{l}\text { inpu! power } \\
\text { (W) }\end{array}$ \\
\hline & & 142 & 49.6 & 567 \\
\hline & & 137 & 49.8 & 507 \\
\hline & & 120 & 50 & 498 \\
\hline & & 116 & 50.1 & 519 \\
\hline & & 111 & 50.3 & 549 \\
\hline & & 180 & 29.7 & 397 \\
\hline Point (II) & optimal voltage & 172 & 29.8 & 375 \\
\hline & $=164(\mathrm{~V})$ & 163 & 30 & 351 \\
\hline Speed $=865$ & Optimal freque. & 159 & 30.2 & 390 \\
\hline (rpm) & $=30(\mathrm{~Hz})$ & 153 & 30.3 & 399 \\
\hline
\end{tabular}


استخدام الشبكة العصبية الاصطناعية في تشغيل الآلة المثية المغذاة بتردد متغيز عند أقصى كفاءة

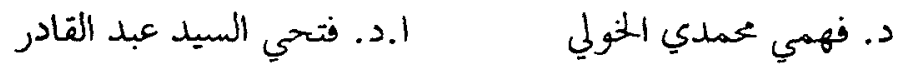

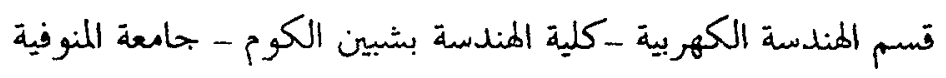

عند تغيير تردد الجهد المغذى الآلة الحثية فانه يتم عادة تغيير قيمة هذا المجهد بحيث تظل النسبة بين

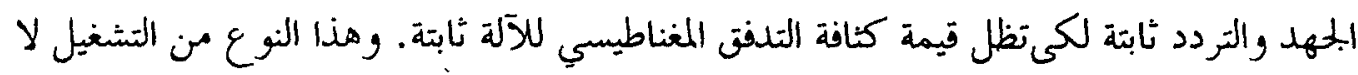
يؤدى إلى اللحصول على أقصى كفاءة للآلة عند السرعات والأحمال المختلفة.

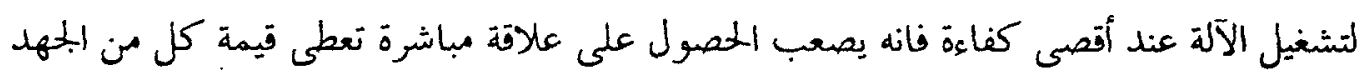

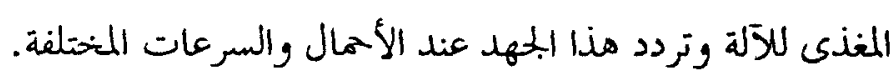
هذا البحث يقدم كيفية استخدام النبكة العصبية الاصطناعية لتشغيل الآلة الحثية عند أقصى كفاءة.

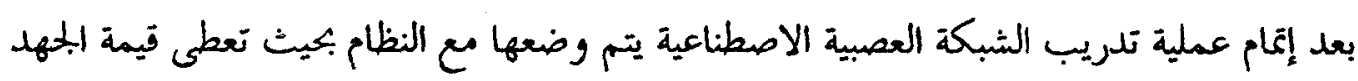
والتردد المطلوين للحصول على أقصى كفاءة طبقا لقيمتي الحمل والسرعة للآلة.

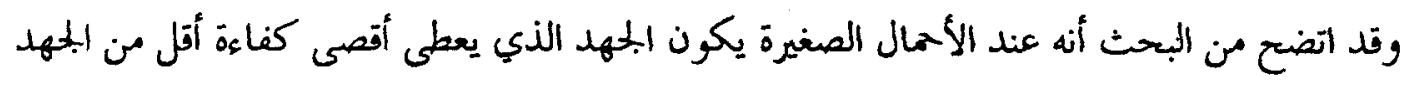

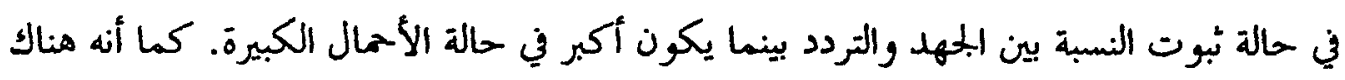
حدود لزيادة السرعة في حالة الأمال الكبيرة. وقد أثبتت النتائج العملية والنظرية كفاءة استخدام الشبكة العصبية الاصطناعية في تشغيل الآلة الحثيــة عند أقصى كفاءة عند السرعات والأحمال المختلفة. 